is quite at variance with the real facts and although a defective knowledge of small-pox may be excusable in a German author it is certainly surprising that an English translator should have passed the statement without comment. That it was allowed to pass, however, seems to indicate that amongst medical men who have not had much practical experience of small-pox there is a somewhat exaggerated idea of the efficacy of vaccination. It is fully recognised nowadays that the protection conferred by vaccination lapses after a variable number of years and that too often small-pox, if then contracted, assumes an unmodified and possibly fatal form. I have myself seen confluent and entirely unmodified small-pox only ten years after vaccination, but such cases are fortunately very rare and quite exceptional. 20 years after vaccination, however, unmodified small-pox is by no means uncommon.

As regards the illustrations themselves, they are reproductions of photographs taken by $m e$ in the Birmingham epidemic, 1892-95. It is to be regretted that the author did not communicate with me before making use of them. He could then at least have made sure that he had the facts relating to them correctly. As it is, he states concerning the unmodified cases: "None of the four cases depicted were protected by vaccination," which statement, taken literally, is obviously quite true. But if the author intends to imply (as from the context it is clear that he does) that none of them had ever been vaccinated, then he is certainly in error. I have looked up my original photograph of Case xxxv. B, 1, which he describes as "an extremely severe case of confluent smallpox in a man, ayed 23 , on the tenth day of the disease," and I find the following note written on the back: "Ernest $\mathbf{S}$ 23 years, vaccinated, four marks, fair size and foveation; photo taken tenth day." I remember the case quite well as the poor fellow remained in hospital for an unusually long time owing to serious complications. The value of vaccination in conferring protection against small-pox for a time has been so completely established as to be beyond the pale of scientific controversy, but reckless statements such as the one in question in a presumably scientific work can only bring the operation into the gravest disrepute and go far to explain the bitterness of those who are opposed to it.

I am, Sirs, yours faithfully,

Town Hall, Leicester, Ap:il 6th, $1903 . \quad$ C. Killick MilladRd,

\section{CONTRACT PRACTICE IN THE COUNTY OF DURHAM.}

To the Editors of THE LANCET.

SIRS,-For four years a struggle has been going on in the county of Durham to obtain increased remuneration for medical attendance on the miners. In some places the higher rate has been easily obtained, in other places there has been delay, whilst in a few places the struggle has been somewhat keen. At the present time in the outskirts of the cathedral city of Durham a very strong and bitter spirit is shown by the miners of this district. Having stoutly rejected the demand made by the local practitioner who had served the miners so well for some eight years, they obtained the services of an outsider; they canvass for him, they coerce their fellow-men to become his patients, and they sing his praises in every cottage; but after a time certain events happen which demonstrate very clearly that the skill displayed by the outsider is not all that may be desired.

The County of Durham Medical Union has quietly and very certainly made up its mind not to associate in any way with a medical man who tramples under fuot all that is honourable in the profession. 'This union is heartily :upported by all the consultants of the north of England. When miners strike for more pay and any men are found who are ready to work at the lower rate, they are dubbed "blacklegs," and are likely to be treated with nuch violence by those on strike. Medical men cannot resort to violence towards thone who are willing to take the lower rate of pay (and so take away the practice of a medical man), but the only course they can adopt is to hold aloof as a bicly and a union and not in any way to associate with one who bas lont all dignity and honour The miners in this particular instance would fain compel the medical union to recogni-e and associate with the man of their choice without any regard to principles.

In the year 1899 I sent a printed appeal to the medical schools of Scotland and the North of England pointing out that a struggle was going on in the county of Durham for increased remuneration and we trusted to the dignity and uprightness of our brethren in the profession not to take advantage of the offers made by the miners. We think that this appeal was noticed in some way; at any rate, we have been assured that the students readily grasped the situation and expressed a loyal feeling. It is, however, disappointing to find that there are practitioners still existing who wish to be informed as to the principle involved; that if the miners should after a time give $9 d$. instead of $6 d$. per fortnight to the man introduced by them no opposition need be continued; that the dispute is now at an end. But this is not so; the dispute is not ended until the old practitioner is reinstated and the proper remuneration is settled. Again, some ask how long must this condition of strife continue. Our reply to this is the same as stated above-viz., so long as the old practitioner is opposed and the proper remuneration is withheld.

I have written all this at some length in order to explain clearly our position, and trusting to the good spirit of your readers that we shall have the help and sympathy of the whole of the profession.

I am, Sirs, yours faithfully,

EDWARD JePson,

President, County of Durham Medical Union.

Durham, April 15th, 1903.

\section{BLISTERING IN CHRONIC SKIN DISEASES.}

To the Editors of THE LANCET.

SIRs,-Dr. G. Norman Meachen ${ }^{1}$ has kindly given the information which I failed to obtain from the latest dermatological text-books in my possession. I was not aware until now that vesication had ever been attempted with a view to eradicate psoriatic patches. It might interest Dr. Meachen to know that patient No. $3^{2}$ is still under treatment by vesication, and that during the past fortnight several commencing patches of psoriasis on the face, back of hand, and at junctions of the ear and scalp have disappeared after one good blistering. When a patch is large and to all appearance stationary, it seems that liquor epispasticus has to be applied on two or three occasions ere any blistering effect is produced. I may add, in conclusion, that there has been no recurrence of psoriasis on any of the areas cleared by vesication.-I am, Sirs, yours faithfully,

JoHN WISHaRT, M.B., Ch.B., B.Sc. Aberd.

Bedlington, R.S.O., April 18th, 1903.

\section{ETHYL CHLORIDE.}

\section{To the Editors of THE LANCET.}

SIRs, - I wish to correct an omission in the printing of my article on ethyl chloride in THE LANCET of April 4th, p. $95 \%$ The shortest case of anæsthesia in the 77 dental cases is stated to be 3 seconds, whereas really it was 30 seconds. This is an important difference. Perhaps I may be allowed to say that Messrs. Duncan and Flockhart are now making pure ethyl chloride, free from merhyl chloride, for inhalation. Thanking you in anticipation, I am, Sirs, yours faithfully,
Birmingham, April 20th, 1903
W. J. MoCardie.

** It will be seen on close inspection that the apparent error was due to a failure of the character 0 to print and not to its being left out.-ED. $\mathrm{L}$.

\section{A PROTEST AGAINST DIRT. \\ To the Editors of THE LANCET.}

SrRS, - In these days, when the sterilisation of everything from milk to toothpicks and po-tage stamps is demanded, it give: one pause to notice the small concern there seems to be for cleanliness as opposed to filth. I allude to the absolutely disgusting circumstances attending the delivery of food in London. Meat and fish are frequently carried on open platters exponed to dunt and dirt of all kinds. Bread is put in a basket slung over the carrier's shoulder, where it rubs against his not too clean coat. If he wishes to rest the banket is put down and for the better comfort of the carrier he sits in it, broad and all. The other day I saw an elaboration of this method, the boy sitting upon a loaf which he had taken from the barket and placed on the pavement. I may

1 The Lancer, April 18th, p. 1126

Tre Lancet, April lith, p. 1030 